\title{
Design Criteria-Based Probabilistic Estimation Method for Aged Apartment Remodeling Projects in Korea
}

\author{
Jun Kim ${ }^{\mathrm{a}}$, Heesung Cha* \\ ${ }^{a}$ Ajou University, Worldcup-ro 206, Suwon, South Korea
}

\begin{abstract}
As apartment get older, it is required to extend the life of the buildings through remodeling and reconstruction. In this situation, members of the apartment choose one of two options. The most important thing in this choice is economical feasibility, which is greatly influenced by the construction cost. There are many cases of reconstruction projects, and accurate construction cost can be calculated. However, remodeling projects are very rare and it is difficult to calculate accurate construction cost. In addition, the remodeling is not only difficult for the members to communicate the design criteria to contractors, but also takes time to reflect them in the estimation, which also affects the decision making. Therefore, this study proposes an estimation method that can integrate the design criteria with in cost. To do this, this study analyzes design criteria based on the previous remodeling cases and classifies them to derive Design Criteria that are required by the members. And it also proposes a range of construction cost by introducing range estimation process to measure the effect of construction cost on each design criterion. In conclusion, this study has been developed an easy-to-use estimation program by combining Excel and Sketchup software. If remodeling cases accumulate in the future, the accuracy and usability of the program are expected to increase.
\end{abstract}

(C) 2019 The Authors. Published by Budapest University of Technology and Economics \& Diamond Congress Ltd.

Peer-review under responsibility of the scientific committee of the Creative Construction Conference 2019.

Keywords: Apartment Remodeling, Influence Analysis, Design criteria, Construction Cost, Estimation

\section{Research Background and Purpose}

In South Korea, apartments comprise the majority of residential buildings. Many apartments were built under national policies between the 1970s and 1990s. As the apartments become old and degrade as time progresses, owners wish to construct new buildings through reconstruction. Many apartments have been reconstructed accordingly. In the 2000s, however, wastage of resources became an important concern, and remodeling using the existing structures was recommended instead of reconstruction in South Korea to improve resource utilization.

However, this resulted in problems regarding the estimation of construction cost. The reconstruction cost can be obtained easily by adding the demolition cost to the new construction cost. For the remodeling cost, meanwhile, difficulties arise in the construction cost estimation from the beginning of the project. This is because no large-scale project has applied the task of reinforcing the existing structures and adding foundation to the entire complex including buildings.

Construction companies are providing rough estimations through simple information, and the reliability is low. Therefore, the willingness of companies to participate in the project is low and apartment owners cannot make a decision on the project (Lee 2010). This is because it is difficult to apply the "similar case comparison method and 
Jun Kim, et al., / Proceedings of the Creative Construction Conference (2019) 040

https://doi.org/10.3311/CCC2019-040

expert experience utilization method," the rough estimation methods used widely in the construction industry to apartment remodeling construction. More specifically, although apartments are typical buildings, few remodeling cases have been reported, rendering it impossible to apply the similar case method(Idrus 2011). In addition, it is difficult to apply the expert experience utilization method because construction experts who have performed the corresponding construction are few. Moreover, although construction experts would like to participate in estimation and reflect on construction cost variation factors, the risks were not classified and their effects were neither identified nor quantified (Kang 2004).

Hence, this study aims to propose an estimation method considering the design criteria required for apartment vertical extension remodeling in the beginning of the project to address the aforementioned problems. Meanwhile, BIM has been used in various areas in the construction industry recently. BIM provides visual information, rendering the communication between the owner and contractor easier. It was confirmed that this characteristic facilitates the communication of remodeling design contents. This study also utilized BIM to facilitate the communication of estimation contents between the owner and contractor in the estimation stage.

\section{Research Scope and Methodology}

Apartment remodeling can be classified into "small-scale remodeling" in which the indoor interior is changed, "medium-scale remodeling" in which additional horizontal extension is performed, and "large-scale remodeling" in which additional vertical extension is included. The target of this study is large-scale remodeling. It is mainly affected household unit increase by adding floors. This type of remodeling also covers underground parking lot extension and structural rehabilitation.

Typically, types of estimations are classified by the accuracy according to the progress of the project. For the purpose this study, the rough estimation has been employed method in order to properly estimate the large scale remodeling projects.

This study attempts to propose an alternative to address the aforementioned problems after analyzing the existing practices, theories, and research through the survey of previous studies.

\section{Preliminary Investigation}

\subsection{Order of Magnitude Estimation Method}

The unit area reference and expert utilization methods are being used as the current remodeling of rough estimation methods. The area reference method calculates the construction cost input to a previous case based on the unit area, and the calculated value is adjusted after an expert assessment. As aforementioned, however, this method produces a calculated value with low accuracy. This is because the current design criteria were not reflected in the construction cost of the past case.

Hence, this study attempts to propose a method of calculating the construction cost by reflecting design criteria. The survey results indicate that rough estimation methods include the cost index, factor estimate, parameter estimate, cube method, unit method, cost weight, performance statistics, condition correspondence, and element (Kim 2018). Among them, both the unit area and element methods, which can reflect design criteria and can be used easily by co-housing association, were used in this study. To include the selected methods in the estimation plan, the area-related contents were examined in the previous cases and were converted into the elements of BIM (Table 1).

Table 1. Area-related elements of apartments and BIM conversion contents.

\begin{tabular}{llll}
\hline Classification & Area contents & \multicolumn{1}{c}{$\begin{array}{l}\text { BIM Conversion } \\
\text { contents }\end{array}$} \\
\cline { 2 - 3 } & Before remodeling & After remodeling & \\
\hline Household configuration & $\sim 10$ pyeong & $\sim 10$ pyeong & 3D object by area
\end{tabular}


Jun Kim, et al., / Proceedings of the Creative Construction Conference (2019) 040

https://doi.org/10.3311/CCC2019-040

\begin{tabular}{|c|c|c|c|}
\hline & $\sim 20$ pyeong & $\sim 20$ pyeong & \\
\hline & $\sim 30$ pyeong & $\sim 30$ pyeong & \\
\hline & $\sim 40$ pyeong & $\sim 40$ pyeong & \\
\hline & $\sim 50$ pyeong & $\sim 50$ pyeong & \\
\hline \multirow[t]{3}{*}{ Building configuration } & Horizontal length & Horizontal length & Building object \\
\hline & Vertical length & Vertical length & \\
\hline & Number of floors & Number of floors & $\begin{array}{l}\text { Division of the } \\
\text { building object }\end{array}$ \\
\hline \multirow[t]{3}{*}{ Complex configuration } & $\begin{array}{l}\text { Total floor area } \\
\text { (ground) }\end{array}$ & $\begin{array}{l}\text { Total floor area } \\
\text { (ground) }\end{array}$ & $\begin{array}{l}\text { Size restriction of } \\
\text { the } 3 \text { D object }\end{array}$ \\
\hline & $\begin{array}{l}\text { Total floor area } \\
\text { (underground) }\end{array}$ & $\begin{array}{l}\text { Total floor area } \\
\text { (underground) }\end{array}$ & \\
\hline & $\begin{array}{l}\text { Underground } \\
\text { parking lot floor }\end{array}$ & $\begin{array}{l}\text { Underground } \\
\text { parking lot floor }\end{array}$ & $\begin{array}{l}\text { Underground } \\
\text { parking lot 3D } \\
\text { object }\end{array}$ \\
\hline
\end{tabular}

The household configuration is the information for dividing each household by size. Pyeong(1Pyeong equals 3.3 square meters) information is entered because each household exhibits different internal work and wall proportions. The building configuration is the information for distinguishing the information of each building. BIM allowed the user to create a three-dimensional (3D) model by drawing a construction area and input detailed information (horizontal length, vertical length, and the number of floors). The complex configuration is the information for distinguishing the information of the entire complex. This content can be obtained by adding all the data of the subunits in a detailed estimation. However, as this study addresses rough estimation, all data are not entered in the subunits. Therefore, the complex information was entered separately.

\subsection{Design criteria of apartment vertical extension remodeling}

Apartment vertical extension remodeling is rare because only a few cases occurred in the 2010s. Nevertheless, typical features for research could be found in several cases and data. It appears that the typical features occurred even though multiple construction companies had built apartments for multiple owners because the "wall column structure" was typically used for increasing productivity and reducing cost. No significant difference was found in the structure because the wall column structure was used. Despite similar forms, however, the number of design plans can be countless and unpredictable when they are changed by remodeling. Therefore, design criteria are limited by the surveyed contents. Design criteria have already been classified by Yoon (2013). As these design criteria only classified the types of remodeling that may exist, rough classification for rough estimation is required.

Hence, design criteria were derived by collecting the design criteria proposed by Yoon (2013) and previous cases. The derived design criteria were classified as follow Table 2.

Table 2. Apartment remodeling design criteria.

\begin{tabular}{|c|c|c|c|c|c|}
\hline Classification & Detailed classification & Detai & & & \\
\hline \multirow[t]{2}{*}{ Area } & Number of core extensions & None & 1 & 2 & 3 \\
\hline & Degree of balcony extensions & None & $0-3 \%$ & $4-7 \%$ & $8-10 \%$ \\
\hline \multirow[t]{4}{*}{ Parking lot } & Ground parking lot extension & None & $\sim 50$ cars & $\sim 100$ cars & $\sim 150$ cars \\
\hline & Deck parking lot extension & None & 1 floor & 2 floors & 3 floors \\
\hline & Underground parking lot extension & None & 1 floor & 2 floors & 3 floors \\
\hline & E/V - underground parking lot connection & None & 1 floor & 2 floors & 3 floors \\
\hline Structure & Structural safety diagnostic rating & $\mathrm{A}$ & B & $\mathrm{C}$ & \\
\hline
\end{tabular}


Jun Kim, et al., / Proceedings of the Creative Construction Conference (2019) 040 https://doi.org/10.3311/CCC2019-040

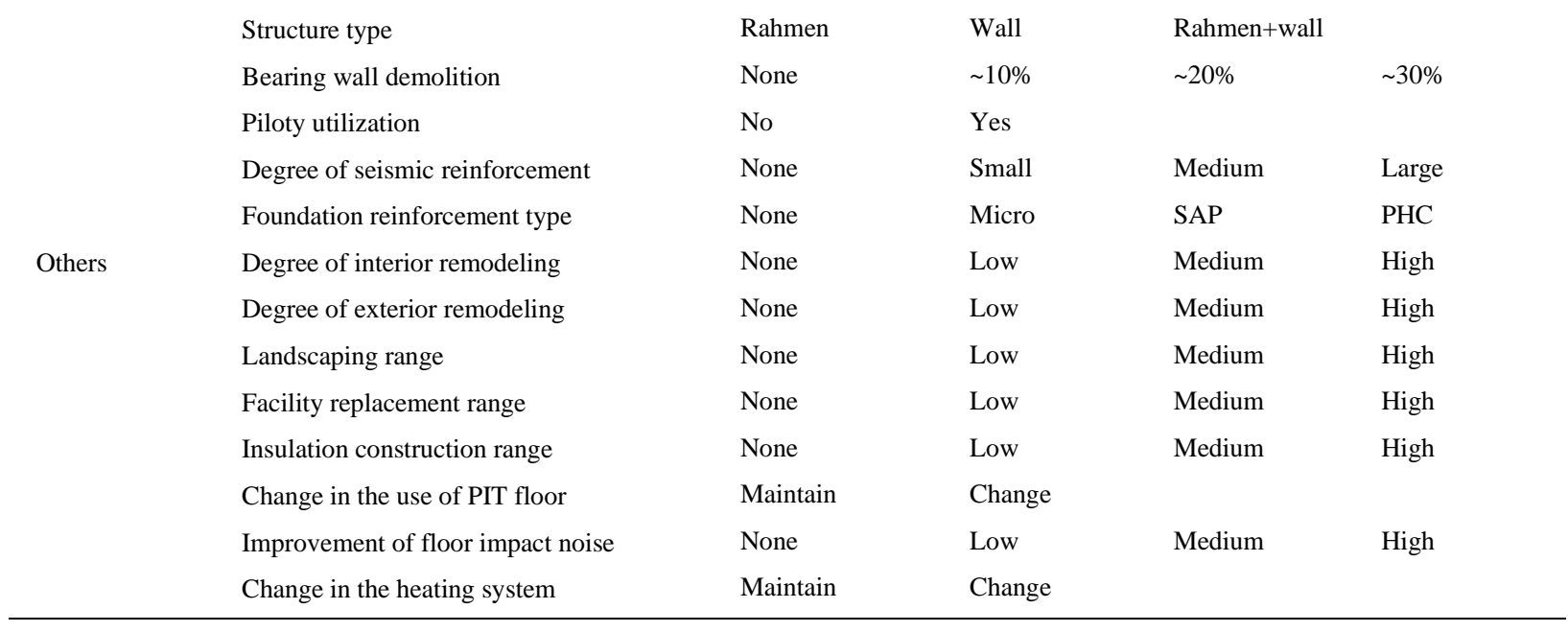

The design criteria were classified into area, parking lot, structure, others. For each classification, from two to eight detailed classifications exist. For each detailed classification, from two to four options are available. The area design criteria is related to the area of an apartment, and pertains to the number of added cores and degree of balcony extension. The parking lot design criteria includes ground and underground parking lots, and pertains to the degree of ground parking lot extension, installation of the deck parking lot, number of added underground parking lot floors, and connection of elevators to underground parking lots. The structure design criteria is related to the condition of a structure. It pertains to the structural safety diagnostic rating, structure type, degree of bearing wall demolition, Piloty utilization, degree of seismic reinforcement, and degree of foundation reinforcement. Moreover, design criteria are available for determining the levels of interior modeling, exterior modeling, and landscaping; meanwhile, other design criteria are used for examining facility replacement, insulation construction, change in PIT floor usage, improvement in floor impact noise, and change in heating system.

\subsection{Construction cost change according to design criteria}

Interviewing experts in apartment vertical extension remodeling regarding construction cost change reveals risks that are unidentifiable and different from those of new construction. This was attributable to insufficient samples as the cases were few and design criteria are many, as mentioned above, owing to the nature of remodeling and because the condition of the current building is different for each remodeling case. Among them, this study was conducted to emphasize that the construction cost varies significantly depending on each design criteria. In a similar previous study, Kang (2008) proposed the following as the characteristics of remodeling: the number of work groups that can be input, core type, elevator location, elevator availability, exhaust/pipe duct availability, width of building interior, balcony demolition, and demolition of nonbearing walls. Kang stressed that each element must be considered because it affects the process. This study attempted to quantify the increase and decrease in the construction cost of each design criteria proposed above through consultation with experts 
Jun Kim, et al., / Proceedings of the Creative Construction Conference (2019) 040 https://doi.org/10.3311/CCC2019-040

\begin{tabular}{|c|c|c|c|c|c|}
\hline & \multicolumn{4}{|c|}{ Staircase and Elevator extension(\# of floors) } \\
\hline & & None & 1 & 2 & 3 \\
\hline \multirow{4}{*}{ Demolition } & $\begin{array}{l}\text { Interior } \\
\text { finish }\end{array}$ & $\begin{array}{c}7 \\
0.9 \sim 1.02\end{array}$ & $\begin{array}{c}\text { (7) } \\
0.9 \sim 1.02\end{array}$ & $\begin{array}{c}8 \\
0.90 \sim 1.10\end{array}$ & $\begin{array}{c}\text { 8) } \\
0.90 \sim 1.10\end{array}$ \\
\hline & Frame & $\begin{array}{c}77 \\
0.9 \sim 1.02\end{array}$ & $\begin{array}{c}77 \\
0.9 \sim 1.02\end{array}$ & $\begin{array}{c}8 \\
0.90 \sim 1.10\end{array}$ & $\begin{array}{c}8 \\
0.90 \sim 1.10\end{array}$ \\
\hline & Facility & $\begin{array}{c}\text { (7) } \\
0.9 \sim 1.02\end{array}$ & $\begin{array}{c}\text { (7) } \\
0.9 \sim 1.02\end{array}$ & $\begin{array}{c}8 \\
0.90 \sim 1.10\end{array}$ & $\begin{array}{c}8 \\
0.90 \sim 1.10\end{array}$ \\
\hline & $\begin{array}{c}\text { External } \\
\text { wall }\end{array}$ & $\begin{array}{c}7 \\
0.9 \sim 1.02\end{array}$ & $\begin{array}{c}\text { (7) } \\
0.9 \sim 1.02\end{array}$ & $\begin{array}{c}\text { (8) } \\
0.90 \sim 1.10\end{array}$ & $\begin{array}{c}\text { (8) } \\
0.90 \sim 1.10\end{array}$ \\
\hline
\end{tabular}

Fig. 1. Analysis of the construction cost variation by design criteria and work(part)

Fig 1 shows the analysis of construction cost variation by design criteria and work. In the table, the row represents design criteria and the column represents work. For example, to analyze the relationship between core extension and demolition-interior finish work, the corresponding cell is filled in with a relationship. In this study, the variation in the construction cost was analyzed using the table above, and the results were inserted to an estimation tool. The detailed introduction of the tool and its utilization method are described in Section 4.4.

\subsection{BIM-based Estimation}

In the construction industry, BIM has been applied to various areas recently, including the estimation area. Studies have been conducted to increase the accuracy of estimations by applying BIM to the estimations and studies to propose quantity calculation methods. In this study, it was emphasized that residents can easily utilize estimations for decisionmaking. When the estimation tool BIM is utilized, it is judged that the design contents are presented visually and the residents can set a design plan easily.

\section{Concept of a BIM-Linked Rough Estimation Tool}

Based on the aforementioned previous studies and surveyed contents, the method of linking each estimation with BIM was established. The aforementioned contents were included in the estimation method that involves the following procedure.

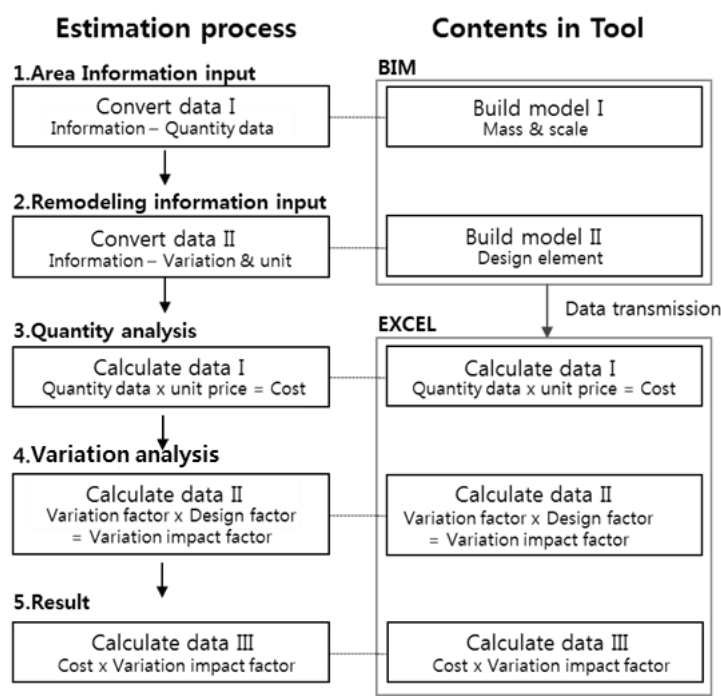

Fig. 2. Contents of the estimation process and the tool 
Jun Kim, et al., / Proceedings of the Creative Construction Conference (2019) 040

https://doi.org/10.3311/CCC2019-040

Estimation was performed in the sequence of area information input, remodeling information input, quantity analysis, variation analysis, and result. (1) In the area information input, the information entered into the BIM model by the user is later converted into the quantity information for calculating construction costs by work. (2) In the remodeling information input, the information generated or entered into the BIM model by the user is converted into the cost variation value of each design criteria. (3) In the quantity analysis, the user inputs the unit price for each work. The construction cost is calculated through the operation of the entered unit prices and the quantity information converted in the area information input step. The contents from this step are processed in a separate Excel spreadsheet based on the contents extracted from the BIM model. (4) In the cost variation analysis step, the user evaluates the variation for each design criteria. The evaluated values are quantified and applied to the calculation of the construction cost. (5) In the result step, the construction cost obtained from the quantity analysis and the cost factor obtained from the variation analysis are subjected to an operation to calculate the final construction cost, which is displayed as a value per area. The concept of the tool created based on the contents above is introduced step by step in the next section.

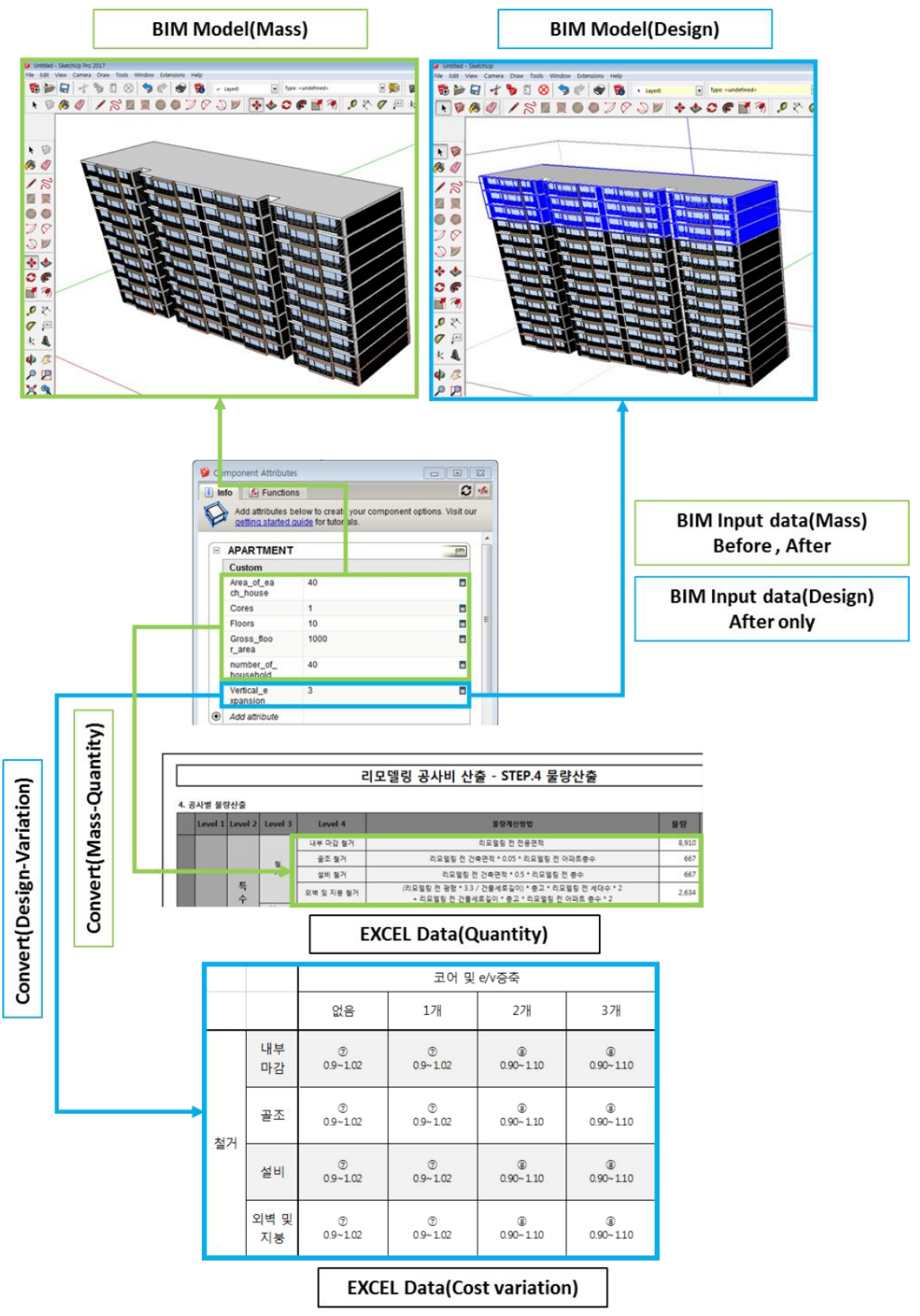

Fig. 3. Information input and information connection in BIM \& EXCEL 
Jun Kim, et al., / Proceedings of the Creative Construction Conference (2019) 040

https://doi.org/10.3311/CCC2019-040

\subsection{Apartment project information input}

In the " Apartment project information input " step, the user arbitrarily models the complex and enters the area-related information. The user goes performs the following steps for modeling.

Step 1. Enter the land area. Step 2. Adjust the shape of the land shown on the screen to match with the actual shape. Step 3. Draw the floor pattern of one apartment building on the land. Step 4. Enter the number of floors, number of households, and Area(Pyeong) information before and after remodeling into the pattern drawn in step 3. Step 5. A 3D object is built on the land according to the results of the input in step 4. Step 6. Repeat steps 3 to 5 until all buildings appear on the land. Step 7. Draw the pattern of the underground parking lot on the land. Step 8. Enter the number of floors and the area of the underground parking lot as well as the parking capacity before and after remodeling into the pattern drawn in step 7. Step 9. A 3D object is built under the land according to the results of the input in step 8. Step 10. Repeat steps 7 to 9 until all parking lots appear under the land.

Based on the information entered in this step, the amount of construction (construction area) is calculated by work. Work is divided into ground and underground, and 36 works exist. For example, the plastering area of one household is obtained through the "area of each household" of the entered information. It is multiplied by the "number of households" to obtain the plastering area of one building. This is multiplied by the number of buildings to calculate the amount of construction required in the project. In Figure 3, the information input window in the middle and the modeling in the top left corner correspond to the contents above.

\subsection{Design criteria input}

In the " Design criteria input " step, the design criteria of remodeling are added to the 3D model created in the previous step. The user adds the contents presented in Table 2 directly to the model. For example, the user can view the model with three floors as vertically extended when selecting " 3 " in the vertical extension. Upon the completion of this process, the 3D model created by the residents is completed. In Figure 3, the information input window in the middle and the modeling in the top right corner correspond to the contents above.

\subsection{Quantity calculation}

In the "quantity calculation" step, quantity is calculated by work based on the information entered into the model. Construction costs by work are calculated by multiplying the calculated quantity with the unit price.

In Figure 3, the quantity calculation table by work at the bottom corresponds to the contents above.

\subsection{Construction cost variation by design criteria}

To reflect the construction cost variation by design criteria to the estimation, the design criteria are quantified into probabilistic construction costs using a method known as Design criteria to cost method. In particular, the key to the quantification part was to reflect the fact that the correlations between each design criteria and work are different than the estimation method. For example, although vertical extension (1-3 floors) was performed, the cost of the finishing work did not vary significantly whether one or three floors were extended vertically. Meanwhile, the foundation work and reinforcement work exhibited significantly higher construction costs. Reinforced concrete also demonstrated an increase. An extreme example is the vertical extension of an underground parking lot. For this vertical extension, the cost of earthwork is highly likely to increase significantly owing to bedrock as the depth of extension increases. For the foundation work, the construction cost increases significantly as well. Among the cases collected for this study, the average construction cost was 1.5 times higher than other cases, and the reason was earthwork.

As shown in the examples above, each design criteria affects the construction costs by work with different degrees and possibilities. 
Jun Kim, et al., / Proceedings of the Creative Construction Conference (2019) 040 https://doi.org/10.3311/CCC2019-040

To distinguish these, the degrees and possibilities of influence are divided in the following figure.

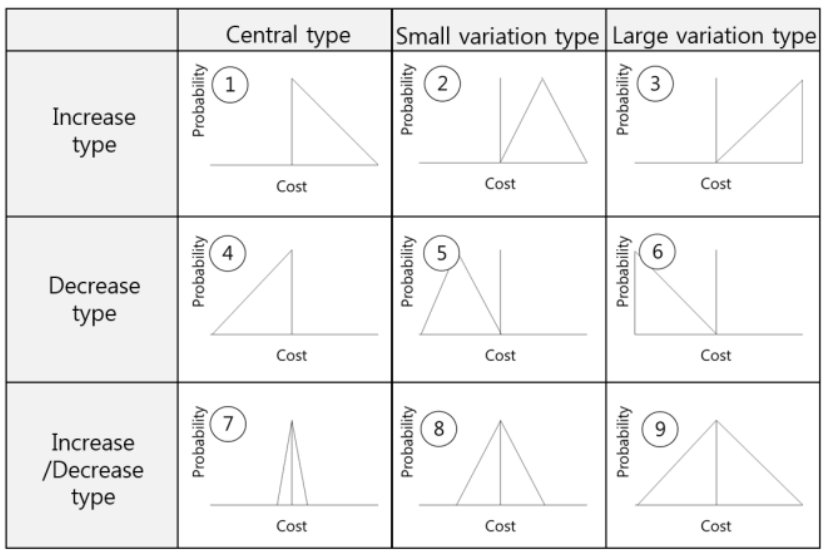

Fig. 4. Analysis of construction cost increase/decrease types according to the probability-cost

The construction cost types were divided into the increase type, decrease type, and increase/decrease type according to the increase or decrease in the construction cost, and into the central type, small variation type, and large variation type according to the variation degree of the probability. For example, for the increase type-central type (number 1), the construction cost is likely to increase, but the possibility is low. For the decrease type-small variation type (number 5 ), the construction cost is likely to be lower than the estimated cost and the possibility is highly likely to be lower than the estimated. The increase/decrease type-large variation type (number 9) is the pattern obtained when the estimated construction cost is high. The construction cost can be higher or lower than the estimated cost, and the increment or decrement is extremely. Next, the construction cost variation range is calculated. The variation amount was between zero and 2 with respect to 1 . For example, when the minimum value is 1 , the maximum value is 2 and the median value is 1.5 for the increase type-small variation type; the construction cost increases or decreases by 1 or 2 times in the low probability and is 1.5 times higher in the high probability. The minimum, maximum, and median values were calculated for the construction cost patterns obtained above. The next step is to convert each probability distribution range derived in the form of a triangular distribution into the value range by substituting the construction cost. In the previous step, construction costs by work were calculated by inputting the area information and design information of apartments. Changes in construction costs by design criteria were applied to the calculated construction costs. For example, if the cost of reinforced concrete work is calculated to be KRW 1 million and the construction cost range has the minimum value of 1 , maximum value of 2 , and median value of 1.5 for the increase type-large variation type, the construction cost is calculated to be between KRW 1 and 2 million. In the final step, the construction costs calculated as ranges are converted into probability distribution forms using @RISK software to introduce the probability concept. In the previous step, only the construction cost range of KRW 1 and 2 million was calculated. The concept that "the median value of 1.5 has the highest probability" was applied to this step.

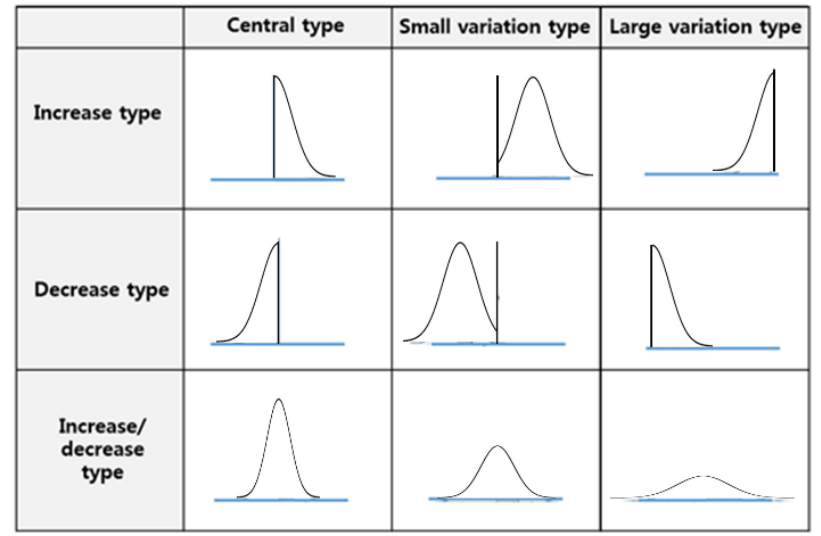

Fig. 5. Construction cost type by design criteria with the probability concept 
Jun Kim, et al., / Proceedings of the Creative Construction Conference (2019) 040 https://doi.org/10.3311/CCC2019-040

Hence, the built-in functions of @RISK were utilized. Consequently, the minimum value, maximum value, and mode could be obtained for each work according to the probability. The final construction cost can be obtained by adding the calculated construction costs of all works.

\subsection{Range construction cost calculation}

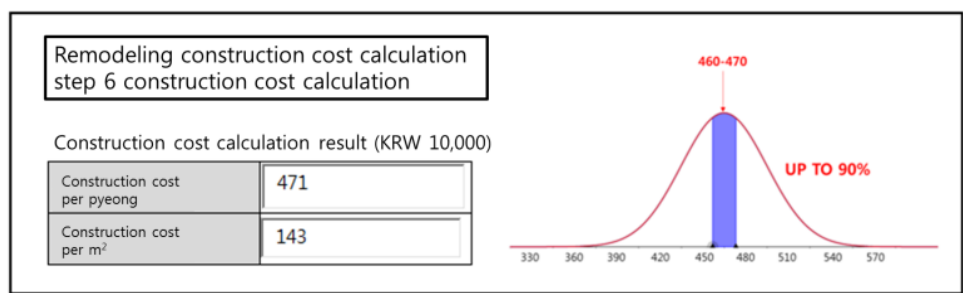

Fig. 6. Final construction cost calculation screen

In the "construction cost calculation" step, operation is performed based on the values entered in the steps above to display the calculated construction cost on the screen. The construction cost per area is displayed for the residents to easily judge the appropriateness of the cost. In addition, the range of the construction cost is calculated through probability statistics to increase its reliability.

\section{Conclusion}

In this study, the problem in estimating for large-scale remodelling apartment buildings has been identified. Also, a new approach in estimating the projects by integrating BIM models with design criteria. Hence, it was possible to positively reflect the design criteria that were not reflected in previous estimations, and the estimation accuracy is expected to be increased. Specifically, the design criteria of remodeling has been derived, and the degree of influence of each design factor on each type of work has been analyzed. This is meaningful in that the existing practitioners have transformed what expert perceived through experience and intuition into specific figures. In addition, the range value is derived as numerical value that the range of each design element can be different. The residents would be able to prevent project duration extension arising from communication problems with the estimation company if this tool were used. Moreover, the tool will be highly beneficial for the decision-making of the resident union by facilitating the decision-making of the residents themselves on the design. If further remodeling cases are analyzed in the future, the accuracy of estimation and usability of the results of this study is expected to be further improved.

\section{Acknowledgements}

This research was supported by the residence environment project program, through the Korea Agency for Infrastructure Technology Advancement, funded by the Ministry of Land, Infrastructure and Transport.(19RERPB099826-05)

\section{References}

[1] Yoon. Y., "The methodology of the apartment remodeling for supporting the customized renovation", land \& housing institute, korea, 2013

[2] Idrus, A., Nuruddin, M. F., \& Rohman, M. A. , Development of project cost contingency estimation model using risk analysis and fuzzy expert system. Expert Systems with Applications, 38, 2011, 1501-1508. http://dx.doi.org/10.1016/j.eswa.2010.07.061

[3] Kang. S, Hwang. Y, Kim. K,A Scheduling Method Of Dismantling Work Considering Specific Condition Of Remodeling Project, Journal of KICEM, 9, 2011, 104-116 https://doi.org/10.1080/01446193.2018.1512750

[4] Lee. K, “ Remodeling and cost”, Korean Remodeling Association, korea 2016

[5] Kim. J, Cha. H., A Probabilistic Risk-based Cost Estimation Model for Initial-Satge Decision Making on Apartment Remolding Projects, Journal of KICEM, 17, 2018, 70-80 https://doi.org/10.6106/KJCEM.2016.17.2.070 